\title{
The Construct of Online Attention Dimension of Tourists to Economy Hotel in Xi'an ---The Exploration of the Grounded Theory
}

\author{
Lu Pang, Junyi Li, Gaojun Zhang \\ Department of Tourism \& Environment, University of Shaanxi Normal Xi'an, Shaanxi Province, China \\ paulapang123@163.com, lijunyi9@snnu.edu.cn
}

\begin{abstract}
With the rapidly development of domestic tourism, the online reviews on hotels and tourism service are the most important source for tourists due to the network technology and online communication. Online reviews can have a significant influence on individual travelers as well as an impact on the competitive reality of the tourism sectors as a whole. Therefore, we had analyzed the tourist reviews about three famous economy hotels (i.e.HOME INN, Hanting Express, JINJIANG INN) in Xi'an from Ctrip.com, a major online travel agency in China by the Grounded Theory approach, and attempted to construct online attention dimension of tourists to economy hotels. The results of the analysis, constructed online attention into five major sections: surrounding factors (i.e. convenient transportation, shopping/entertainment, sensory distance), cost performance factors (i.e. room cleanness, price), service factors (i.e. service attitude, front office, breakfast, working efficiency), internal factors (i.e.facilities, internal decoration) and comfortable factors (i.e. cosiness, sweetness (togetherness)). As a result, this article is helpful to make the hotel management understand its advantages, and to make wisdom advise for individual travellers and economy hotels in the future.

Index Terms - Online Attention, Online Review, the Grounded Theory, Economy Hotel
\end{abstract}

\section{Introduction}

With the development of domestic tourism, economy hotels have become the first choice of tourist. According to CNNIC, as of June, 2011, 81.3\% of the online users have been reserving hotel on the Internet, and economy hotel booking online is $44.4 \%$.The rapid growth of web 2.0 applications, which empowers Internet users and allow two-way information communications in travel and tourism, has generated an enormous number of on-line user-generated contents (UGC) on hotels, travel destinations, and travel services [1]. Increasing number of travelers are using the Internet to seek destination information and to conduct transactions online, "sharing tourism experience or feeling are producing amounts of information " [2].Consumer reviews can be seen as additional holiday components, ultimately enriching the holiday experience at a relatively low cost, whilst improving the comparability, transparency and trustworthiness of holiday offerings [3]. Through positive online feedback new customers can be acquired and retained at a relatively low cost. Alternatively, negative feedback could inhibit customer acquisition and reduce the value of brand in the longer term [4]. Online information has significant influence on consumer purchase decision [5]. Vermeulen and Seeger revealed that positive as well as negative reviews increase consumer awareness of hotels, whereas positive reviews, in addition, improve attitudes toward hotels [6]. Ye and Law confirmed that positive review can bring more online sales [7].

In the current study, we made a start in systematically exploring the satisfication of economy hotel using online hotel reviews. Zhu and $\mathrm{Lu}$ found that the facilities, front office procedures, house keeping service, and room size are important factors contributing to the consumer perception of the hotel standards as opposed to the star rating of the hotel [8]. Wu suggested that the sound insulation of rooms and catering service environment should be improved [9]. Xiong and $\mathrm{Xu}$ confirmed that customers have a high level satisfaction about the service quality in the economic hotel and are concerned about room status, noise, Internet and hair dryer, and compared with the other factors, Internet reservation system as well as breakfast service need to be improved, and service quality provided in the east part of China is better than that in the west and middle [10]. Previous researches mainly concerned on economy hotel service, but few explored online attention from the point of tourists' view through online reviews.

\section{Research Methodology}

The Grounded Theory approach was proposed by Barney Glaser and Anselm Strauss in 1967[11] and is a scientific research methodology. It is defined as a qualitative research method using a systematic set of processes to develop an inductively derived the Grounded Theory approach about a phenomenon [12-13]. The Grounded Theory has been used extensively across a variety of social science disciplines. Petri Hottola was the first person who applied the Grounded Theory approach in [14]. Tussyadiah and Fesenmaier confirmed that online shared videos can provide mental pleasure to viewers by stimulating fantasies and daydreams, as well as bringing back past travel memories [15]. At domestic, Yang and Lu, et al [16-18] tried to apply the Grounded Theory approach on tourism research to discuss the characteristic of tourists behavior. Traditional Grounded Theory approach emphasized on obtaining "the most real society" from the original information [18], that is to say, personal unstructured reviews are the predominant data collection method. 


\section{Study}

\section{A. Data}

Ctrip.com is one of largest online tourism booking websites, in which both tourism company details and usergenerated content are presented. We collected available tourist reviews information about three famous economy hotels (i.e.HOME INN, Hanting Express, JINJIANG INN) from Ctrip.com in Xi'an. Ctrip.com held information on 53 economy hotels in Xi'an. Among these hotels, 30 are no longer available for online bookings, and we thus deleted these unavailable hotels from the dataset. Our final dataset contains 23 economy hotels. For each hotel in our dataset, we collected all consumer reviews for the hotels from the time October 2010 to October 2011, which gave a total of 907 consumer reviews.

\section{B. Findings}

The findings of the qualitative survey of 907 consumer reviews by the Ground Theory were classified into five major categories, "surrounding factors", "cost performance factors", "service factors", "internal factors" and "comfortable factors". Surrounding factors included convenient transportation, shopping/entertainment and sensory distance. Cost performance factors contained room cleaness and price. Service factors consisted of service attitude, front office, breakfast and working efficiency. Internal factors included facilities and internal decoration. Comfortable factors consisted of cosiness and sweetness (togetherness).

1) Surrounding Factors. Compared to top grade hotels with high quality and comprehensive service, economy hotels mainly focus on limited services. Therefore, surrounding factors of economy hotels was apparently important. Surrounding environment including traffic, shopping, numerous dining and entertainment places make up its simple supporting facilities, and satisfy consumption for consumers. $20 \%$ tourists mentioned convenient transportation, because the main target of economy hotel is businessmen and leisure tourists who put the transportation on the first position. What's more, Xi'an, as one of four great ancient cities, has so much culture and history sites, which determines that transportation is the critical point for tourists. On the other hand, economy hotel cannot meet the need of shopping/ entertainment for tourists except basic lodging, and sensory distance can be defined as the position of hotel have a short distance to downtown, train station or airport express bus station, so the tourists can go to these place conveniently. Both are definitely the reason for tourists to concern surrounding factors.

2) Cost Performance Factors. Economy hotel has advantages in price and lodging, which are attractive to tourists, especially for those who are sensitive to price. When tourists purchase products from economy hotel, they just pay for the room rather than paying much for other additional products. There were 267 online tourists mentioned that the sample hotels are clean and tidy. Lodging service was considered to be the core value of economy hotel, and clean and tidy room was not only the basic requirement for consumer, but also conveyed direct sensory information.

3) Service Factors. There were $7.72 \%$ consumers to mentioning staff attitude. The reason is in term of consumers, staffs in hotel have a significant relationship with them from the first day they came until the day they left. Positive attitude can make consumer feel comfortable and pleased as well as increasing the sense of dependence. One tourist mentioned "he front office had no idea about tourism information", which shows that tourists seemed to be desired to know more about tourism information form the front office, but apparently, the front office service still lagged behind in the tourists' need change. Secondly, tourists mentioned breakfast and efficiency, though they pay little attention to them. That reason might be the economy hotel emphasizes that one person take more than one jobs in order to save cost, which leads to a bad impact on efficiency.

4) Internal Factors. Based on the results of reviews, internal factors were determined by attributes such as facilities and room decoration. $13.01 \%$ tourists mentioned facilities in hotel. The key elements associated with facilities of a hotel were found to be warm water, parking or strong signal and so on. Room decoration of the hotel seemed to be one of the key attributes allowing customers on holiday to feel back at home. In most reviews frequently mentioned words related to the internal factors are "big bed", "nice wall color" and "free internet", etc.

5) Comfortable Factors. Comfortable factors were perceived as both cosiness and togetherness, which were the tendency to create an inviting space for consumers and make them feel at home. This factor is in accordance with the economy hotel theme, such as JinJiang Inn's: one family, one night, one good meal.

\section{Conclusions and Discussions}

We had analyzed the user reviewing practices on Ctrip.com, a major online travel agency in China, and attempted to construct online attention of tourists to economy hotels. The results of the analysis, identified through the qualitative phase, constructed online attention dimension into five major sections: surrounding factors (i.e. convenient transportation, shopping/entertainment, sensory distance), cost performance factors (i.e. room cleanness, price), service factors (i.e. service attitude, front office, breakfast, working efficiency), internal factors (i.e. facilities, internal decoration)and comfortable factors (i.e. cosiness, sweetness (togetherness) ) .

With the advent of mass tourism, online consumer reviews about travel destinations, hotels, and tourism service have thus become important sources of information for travelers [19]. Hotel selecting could be described as an information-intensive process on the era of information. There has been a significant change in the primary customers of economy hotel. Marketers should notice that positive consumer reviews have a much lager impact on consumer 
behavior, and let them understand what their advantages are and what their targets need. On the other hand, it has significant meaning for hotel managers using the feedback information from tourists to control their products quality. This particularity needs to be taken into account to transfer other sectors.

Firstly, third-party websites served as trusted hotel booking information to their clients offer numerous first-hand comments and ratings posted by travelers assessing, discussing, and dissecting virtually most hotels and restaurants in any major city, which incredibly changed the way of tourist attention to economy hotels. Secondly, economy hotel should take advantage of city supporting facilities, especially traffic and around environment to satisfy tourists need. Thirdly comfortable factor play a hygiene role for tourists sensory. However, this sensory does not cause unhappy and attention of tourists until it turn out to be in a totally bad condition. Consequently, hotel manager should take this sensory seriously for the future, and make sure to strengthen intense sense of belong for consumer. Finally, this paper confirmed that tourist has the tendency to be more rational and more mature, which has a high attention for hospitality service, such as traffic, parking or free Internet instead of price attention. That is to say, with the development of information technology, tourists' demand level have transformed from whether with or without to whether good or bad. Therefore, economy hotel should improve more professional service to adapt to tourist need change. All in all, marketers need to learn how to control this new and powerful force and react quickly.

However, the hotels we selected for this study are located in the same palce. (i.e.xi'an ). It could be argued that local economy and target consumers of hotels are different to a large degree. Therefore, the restricted area scope of this study should be highlighted as a limitation to its validity and findings. At the same time, this limitation presents the opportunity of replicating this type of research in other area settings.

\section{Acknowledgment}

The authors would like to give sincere thanks to Professor J.Y. Li for kindly providing me with relevant instructions and J.Z. Gao for help on the statistical analysis of the Grounded Theory approach.

\section{References}

[1] M. Sigala, "E-service quality and web 2.0: Expanding quality models to include customer participation and intercustomer support", The Service Industries Journal, vol. 29, no. 10, pp. 1341-1358, October 2009.

[2] Z-L. Zhan, et a, "An Analysis of the Co-occurrence Phenomenon of Scenic Areas in Online Travel Notes". Tourism Science, vol. 25, no. 2, pp. 39-46, April 2011.

[3] A. Papathanassis, F. Knolle, "Exploring the adoption and processing of online holiday reviews: A grounded theory approach", Tourism Management, vol. 32, no.2, pp. 215-224, April 2011.

[4] C. Dellarocas, "The digitization of word-of-mouth: promise and challenges of online feedback mechanisms", Management Science, vol. 49, no. 10, pp. 1407-1424, October 2003.

[5] E. K. Clemons, G. Gao, "Consumer informedness and diverse purchasing behaviours: traditional mass-market, trading down, and trading out into the long tail", Electronic Commerce Research and Applications, vol. 7, no. 1, pp.3-17, Spring 2008.

[6] I. E. Vermeulen, D. Seegers, "Tried and tested: The impact of online hotel reviews on consumer consideration", Tourism Management, vol. 30,no. 1, pp. 123-127, February 2009.

[7] Q. Ye, R. Law, "The influence of user-generated content on traveler behavior: An empirical investigation on the effects of e-word-of-mouth to hotel online bookings", Computers in human behavior, vol. 27, no. 2, pp. 634-639, March 2011.

[8] F. Zhu, Z. Lu, "The Post-purchase Evaluationof The China's Star Rated Hotel Service Quality: A Content Analysis of Guest Comments on Third Party Hotel Booking Websites", Tourism Tribune, vol. 21, no. 5, pp. 86-90, 2006.

[9] J. F. Wu, "IPA On the Economy Hotel Service Quality in China-Based on the Survey of Home Inn \& Jinjiang Inn", East China Economic Management, vol. 21, no. 11, pp. 95-98, November 2007.

[10] W. Xiong, J. H. Xu, "A Evaluation on Service Quality of Economic Hotel in China: A Content Analysis of Guest Comments on Website", Journal of Beijing second foreign languages institute, no. 11, pp. 57-67, 2010.

[11] B. Glaser, A. Strauss. The Discovery of Grounded Theory: Strategies for Qualitative Research.New York: Aldine De Gruyter, 1967.

[12] A.L. Strauss, J.M. Corbin, Basics of Qualitative Research: Grounded Theory Procedures and Techniques. Sage, Newbury Park, California. 1990.

[13] K. Charmaz, Constructing Grounded Theory: A Practical Guide Through Qualitative Analysis. Sage, London, 2006.

[14] P. Hottola, "Culture confusion intercultural adaptation in tourism", Annals of Tourism Research, vol. 31, no. 2, pp. 447-466, April 2004.

[15] I. P. Tussyadiah, D. R. Fesenmaier, "Mediating tourist experiences: Access to places via shared videos", Annals of Tourism Research, vol. 36, no. 1, pp. 24-40, January 2009.

[16] Z. Yang, L. Lu, "Analysis on Behavioral Characteristics of Tourism Labor Migrants in Jiuhua Mountain", Resource Development \& Market, vol. 23, no. 2, pp. 171-175, 2007.

[17] X. L. Miao, J. G. Bao, "Grounded Theory of Non-standardized Groups Travel ", Tourism Tribune, vol. 22, no. 8, pp. 48-54, 2007.

[18] J. Gao, Y. F. Ma, "Defects of China's Inbound Tourism from Foreign Tourists' Perspective:An Analyze Based on Grounded Theory Research Paradigm". Tourism Science, vol.24, no. 5, pp. 49-55, October 2010.

[19] B. Pan, T. MacLaurin, J. Crotts, "Travel blogs and the implications for destination marketing", Journal of Travel Research, vol. 46, no. 1, pp. 35-45, August 2007. 